DR. TERESA FLAXMAN (Orcid ID : 0000-0001-8874-3359)

Article type : Systematic review

\title{
Influence of race/ethnicity on prevalence and presentation of endometriosis: A systematic review and meta-analysis
}

\section{Olga Bougie ${ }^{1}$}

Ma. Isidora Yap ${ }^{2}$

Lindsey Sikora ${ }^{3}$

Teresa Flaxman 4

Sukhbir Singh ${ }^{4,5}$

${ }^{1}$ Department of Obstetrics and Gynaecology, Queen's University, 76 Stuart St Kingston ON K7L2V7, Canada

${ }^{2}$ Department of Obstetrics and Gynecology, St. Luke's Medical Center, 279E Rodrigues Sr. Ave, Quezon City, 1112, Phillippines

${ }^{3}$ Health Sciences Library, University of Ottawa, 451 Smyth Rd Ottawa ON K1H8M5, Canada

${ }^{4}$ Department of Clinical Epidemiology, Ottawa Hospital Research Institute, 501 Smyth Rd Ottawa ON K1H8L6, Canada

${ }^{5}$ Department of Obstetrics, Gynecology and Newborn Care, The Ottawa Hospital, 501

Smyth Rd Ottawa ON K1H8L6, Canada

Corresponding Author: Olga Bougie

\author{
Queen's University \\ Department of Obstetrics and Gynaecology \\ Kingston General Hospital \\ 76 Stuart St. \\ Kingston, ON K7L 2V7 \\ Tel: (613)548-7840 \\ Fax: (613)548-1330 \\ Email: bougieo@kgh.kari.net
}

Running Title: Influence of race/ethnicity on endometriosis

This article has been accepted for publication and undergone full peer review but has not been through the copyediting, typesetting, pagination and proofreading process, which may lead to differences between this version and the Version of Record. Please cite this article as doi: 10.1111/1471-0528.15692

This article is protected by copyright. All rights reserved. 


\section{ABSTRACT}

Background: Understanding the impact of race/ethnicity on the prevalence and presentation of endometriosis may help improve patient care.

Objective: To systematically review the evidence for the influence of race/ethnicity on the prevalence of endometriosis.

Search Strategy: CENTRAL, Medline, PubMed, Embase, LILACS, SCIELO, and CINAHL databases, as well as the grey literature, were searched from date of inception until September 2017.

Selection Criteria: Randomized control trials and observational studies reporting on prevalence and/or clinical presentation of endometriosis.

Data collection and analysis: Twenty studies were included in the review and 18 studies were used to calculate odds ratio (OR) with 95\% CI through a random effects model. Methodological quality was assessed using the Newcastle-Ottawa risk of bias Scale (NOS).

Main Results: Compared to White women, Black woman were less likely to be diagnosed with endometriosis (OR 0.49, 95\% CI 0.29-0.83), while Asian women were more likely to have this diagnosis (OR 1.63, 95\% CI 1.03-2.58). Compared to White women, there was a statistically significant difference in likelihood of endometriosis diagnosis in Hispanic women (OR 0.46, 95\% CI 0.14-1.50). Significant heterogeneity $\left(\mathrm{I}^{2}>50 \%\right)$ was present in the analysis for all racial/ethnic groups, but was partially reduced in subgroup analysis by clinical presentation, particularly when endometriosis was diagnosed as self-reported,

Conclusions: Prevalence of endometriosis appears to be influenced by race/ethnicity. Most notably, Black women appear less likely to be diagnosed with endometriosis compared to White women. There is scarce literature exploring the influence of 
race/ethnicity on symptomatology, as well as treatment access, preference and response.

Funding: None.

Keywords: Endometriosis; Race; Ethnicity; Systematic Review; Meta-analysis

Tweetable Abstract: Prevalence of endometriosis may be influenced by race/ethnicity, but there is limited quality literature exploring this topic.

\section{INTRODUCTION}

Endometriosis is a common gynecologic condition, affecting approximately $10 \%$ of reproductive aged women ${ }^{1-3}$. It presents with pelvic pain, painful periods, and infertility and can significantly impact one's quality of life ${ }^{4-6}$. Delay in the diagnosis of endometriosis, spanning on average 7-10 years, is a significant barrier in the management of this condition, leading to years of sub-optimal treatment and possible disease progression $4,7,8$.

Race/ethnicity may influence one's ability to access healthcare and obtain appropriate management for endometriosis through a combination of socioeconomic and genetic influences ${ }^{9,10}$. In the 1960 s and 70 s, several foundational textbooks of gynecology suggested that endometriosis was infrequent in Black women as well as those of low socioeconomic status ${ }^{11,12}$. It is still unclear if there is biological basis for this conviction or if it can be explained by methodological and social bias that existed in the literature around that time ${ }^{13-15}$. Implicit and explicit bias amongst the medical community may have influenced a women's chance of timely and accurate diagnosis of 
endometriosis, depending on her race/ethnicity. In addition to variation in disease prevalence among women of different race/ethnicities, it is also possible that this trait may influence the clinical presentation or therapeutic response. Several studies have attempted to address this question to date ${ }^{4,16-18}$, with varying conclusions. For instance, Missmer et al. ${ }^{16}$ studied the association of patient demographic and anthropometric factors on the incidence of endometriosis in the Nurse's Health Study II cohort. Although this was a prospective cohort study, with excellent follow-up and control for confounding factors, the fact that endometriosis was surgically diagnosed may lead to bias conclusions as women of different ethnicity/race may present with different indications for surgery or symptoms suggestive of endometriosis.

The objective of this study is to systematically review the literature and perform a meta-analysis to determine the influence of race/ethnicity on the prevalence of endometriosis, as well as disease presentation. We are interested in summarizing the evidence in this realm, to understand if specific racial/ethnic groups present in a unique way, in terms of symptomatology, as well as disease severity. Applying a phenomic approach to the diagnosis and management of endometriosis may improve our ability to provide accurate and timely diagnosis ${ }^{19}$. Furthermore, understanding the impact of one's racial/ethnic background on the presentation of this condition will tailor clinicians' approach to each individual patient, from the time that the condition is suspected, through to diagnosis and treatment.

\section{METHODS}

\section{Protocol and Registration}

The study was developed and completed in compliance with the PRISMA guideline $^{20}$. The meta-analysis was registered with the PROSPERO International 
Prospective Register of Systematic Reviews (ref. 42017070665 Available from:

http://www.crd.york.ac.uk/PROSPERO/display_record.php?ID=CRD42017070665) on

July 4, 2017.

\section{Sources}

The search strategy was developed by a health sciences librarian (L.S.). The following electronic databases were searched: PubMed, Medline (via Ovid), Embase (via Ovid), Cochrane Central Register of Controlled Clinical Trials - CENTRAL (via Ovid), Cumulative Index of Nursing and Allied Health Literature - CINAHL (via EBSCOHost), LILACS and ScIELo. The databases were searched from date of the inception to September 30, 2017. In addition, abstracts from the following conferences were hand searched for the preceding five years: AAGL Global congress, ASRM (American Society of Reproductive Medicine), ESHRE (European Society of Human Reproduction and Embryology), ESGE (European Society of Gynecologic Endoscopy), SEUD (Society of Endometriosis and Uterine Disorders), JSGOE (Japan Society of Gynecologic and Obstetric Endoscopy and Minimally Invasive Therapy), ACOG (American College of Obstetrics and Gynecologists), and SOGC (Society of Obstetricians and Gynecologists of Canada). These were selected based on recommendations from content experts. For details of the search performed, see Appendix S1. Endnote software (X8; Clarivate Analytics; Philadelphia, PA) was used to export and organize the abstracts and subsequently remove duplicate publications.

\section{Study Selection}

We included studies that reported on the association between women's race/ethnicity and our primary outcome of interest: prevalence and/or clinical presentation of endometriosis. Studies were included in our meta-analysis if they met 
the following criteria: 1 . Study involved endometriosis, 2 . Study was of a randomized control trial, cohort or case control design, 3. One of the outcomes of interest was defined, 4. English full-text, 5. Minimum of 10 patients involved, and 6. Patients were $>18$ years of age. Studies were excluded if there was no comparison between ethnic populations (i.e. one described within the study). Authors were contacted to obtain the full text article or additional information if inclusion criteria were met based on the information provided in the abstract. The study abstracts were screened by 2 authors (O.B. and M.Y.) with disagreements reviewed and settled by an arbitrator (S.S.). Subsequently, potentially eligible studies underwent a full-text review, by the same authors.

\section{Data Extraction}

Data extraction and assessment of study quality were performed by 2 independent reviewers (O.B. and M.Y.), using standardized data collection forms. Information regarding study characteristics, baseline participant data, and criteria for diagnosis of endometriosis, including presenting symptoms, imaging and surgical findings was extracted from each study. Any discrepancy between reviewers was resolved by discussion and consensus, as well as input from a third reviewer (T.F.).

\section{Assessment of Risk of Bias}

Quality assessment was performed using the Newcastle-Ottawa risk of bias Scale $(\text { NOS })^{21}$, which evaluates study quality based on three perspectives: the selection of the study groups (maximum 4 points); the comparability of the groups (maximum 2 points); and the ascertainment of either the exposure or outcome of interest for casecontrol or cohort studies respectively (maximum 4 points). The Newcastle-Ottawa scale was selected as it is validated for case control and longitudinal studies ${ }^{21,22}$.

Furthermore, it is adaptable to use for various investigational topics and can be used as 
a moderator for subgroup analysis ${ }^{21}$. We considered studies of high quality if NOS score was equal to or greater than five.

Small study and publication bias was evaluated using a funnel plot and statistically tested using Egger's Linear Regression method using Comprehensive MetaAnalysis Software (CMA v3; Biostat; Englewood NJ). Plot asymmetry was determined with a 95\% confidence interval and a two-tailed p-value $<0.05$.

\section{Data Synthesis}

The primary outcome of likelihood of endometriosis diagnosis in each ethnic group was extracted from each study. An odds ratio was calculated using a random effects model with a 95\% confidence interval in Review Manager (RevMan v5.3; Nordic Cochrane Centre, The Cochrane Collaboration; Copenhagen, DK) to compare the odds of diagnosis of endometriosis based on ethnicity. White/Caucasian race/ethnicity was used as the reference category, with comparison made to Black, Asian and Hispanic groups. Pre-specified subgroup analysis stratified by study quality (NOS score $<5$ vs. $\geq 5$ ) was performed to explore heterogeneity using the same methods. As data was extracted, clinical presentation and year of publication (before and after 1990) were identified as key variables that differed between studies and therefore were included in the subgroup analysis as well.

\section{RESULTS}

\section{Study Selection and Description}

An initial query yielded 1180 studies, which was subsequently narrowed to 20 studies in the qualitative review ${ }^{4,13-18,23-36}$ (Figure S1). An overview of the included studies' characteristics and primary outcome is summarized in Table 1. Of the included studies, there were 11 retrospective cohorts, 4 prospective cohort, 4 cross sectional 
surveys and 1 case control study. Eighteen studies were included in the meta-analysis to study the primary outcome of endometriosis prevalence on Black, Asian and Hispanic women compared to White women.

Two studies were not included in the meta-analysis as they reported outcomes of interest in a format not compatible for data synthesis. First, Missmer et al. ${ }^{16}$ examined the incidence of laparoscopically diagnosed endometriosis in the Nurse's Health Study II prospective cohort from 1989 to 1999 . They identified 1,721 incident cases of endometriosis, after 726,205 person-years of follow-up. In multivariate cox proportional hazard models, they found that Black women had lower rate of endometriosis diagnosis compared to White women (RR 0.6, 95\% CI 95\% 0.4-0.9), whereas Asian (RR 0.8, 95\%0.5-1.1) and Hispanic women (RR 0.6, 95\%CI 0.4-1.0) had similar rates of disease compared to White women. They reported the prevalence of surgically confirmed endometriosis for women with and without chronic pelvic pain. Second, Zhao et al. ${ }^{35}$ examined the prevalence of endometriosis related hospitalization based on the Nationwide Inpatient Sample in 1991 and 1992 in the United States. They observed significantly lower rates (per 1000) of endometriosis diagnosis in Black, Hispanic and Asian pacific women compared to White women $(\mathrm{p}<0.001)$. For instance, in 1991, the rate of first diagnosis of endometriosis was 3.4 in Black, 3.2 in Hispanic, 7.7 in Asian and 11.0 in White women, per 1000. This trend maintained for later diagnosis of endometriosis, in both the 1991 and 1992 year analyses.

\section{Risk of Bias}

The median NOS score was 4 (range: 1-8). Eight studies were considered to be of high quality (NOS $\geq 5$ ) and 10 of low quality (NOS $<5$ ). Median score for assessment of selection was 1 (range: $0-3$ ), for comparability 0 (range: $0-2$ ), and for study outcome 3 (range: $0-3$ ). 
Significant publication bias in the reported prevalence of endometriosis of Black women compared to White women $(\beta=5.21, \mathrm{p}<0.001)$ was observed but not when White women were compared to Asian women $(\beta=2.73, p=0.157)$ or Hispanic Women $(\beta=3.18, p=0.168)$ (Figure S2).

\section{Synthesis of Results}

For the primary outcome of likelihood of endometriosis diagnosis, 16 studies compared this outcome between White and Black women (Figure 1A). Compared to White women, Black women were less likely to be diagnosed with endometriosis (OR 0.49, 95\% CI 0.28-0.83). Furthermore, subgroup analysis was performed with studies stratified by clinical presentation (Figure 2A), as well as year of study (Figure 2B). In studies which included women based on surgical or self-reported diagnosis of endometriosis, there remain a significantly decreased odds of diagnosis of endometriosis in Black compared to White women (OR 0.58, 95\% CI 0.45-0.75 for selfreported and OR $0.45,95 \%$ CI $0.25-0.83$ for surgical diagnosis). In women presenting with infertility, there was no significant difference in endometriosis prevalence between White and Black women (OR 0.64, 95\% CI 0.20-2.11), although subgroup analysis by infertility only included 2 studies and 1094 patients. The odds of diagnosis of endometriosis in Black compared to White women was comparable in studies performed before 1990 (OR 0.53, 95\% CI 0.20-0.95) and after 1990 (OR 0.47, 95\% CI 0.23-0.98). Similarly, the odds of diagnosis of endometriosis was comparable in low quality studies (OR 0.53, 95\% CI 0.33-0.86) and high-quality studies (OR 0.45, 95\% CI 0.19-1.05) (Figure S3A).

There were 10 studies examining the likelihood of endometriosis diagnosis in Asian women (Figure 1B). Compared to White women, Asian women were significantly more likely to be diagnosed with endometriosis (OR 1.63, 95\% CI 1.03-2.58). Subgroup 
analysis by clinical presentation demonstrated no significant difference in endometriosis prevalence between White and Asian women when the diagnosis of endometriosis was self-reported (OR 0.80, 95\% CI 0.54-1.19), made surgically (OR 1.61, 95\% CI 0.92-2.82) or when patients presented with infertility (OR 2.03, 95\% CI 0.646.47) (Figure 3A). The odds of diagnosis of endometriosis in Asian compared to White women was greater in studies published before 1990 (OR 1.88, 95\% CI 1.31-2.70) compared to studies published after 1990 (OR 1.57, 95\% CI 0.93-2.64) (Figure 3B). Similarly, the odds of diagnosing endometriosis in Asian compared to White women was greater in low quality studies (OR 2.05, 95\% CI 0.96-4.38) than high quality studies (OR 0.99, 95\% CI 0.70-1.39) (Figure S3B).

Five studies included Hispanic women when looking at diagnosis of endometriosis (Figure 1C). Overall, there was no significant difference in likelihood of endometriosis diagnosis between Hispanic and White women (OR 0.46, 95\% CI 0.141.50). Due to the small number of studies that included this ethnic group, further subgroup analysis was not performed.

When assessing heterogeneity, the analysis for all three race/ethnicity categories demonstrated evidence of moderate to high heterogeneity $\left(\mathrm{I}^{2}>50 \%\right)$. For the race/ethnicity categories where a subgroup analysis by clinical presentation was performed, there was moderate to high heterogeneity demonstrated only in the subgroup where endometriosis was established by surgical diagnosis. In subgroup analysis by publication date, moderate to high heterogeneity was seen (Figures $2 \mathrm{~B}$ and 3B).

This article is protected by copyright. All rights reserved. 


\section{DISCUSSION}

\section{Main findings}

Based on our review, the likelihood of diagnosis of endometriosis appears to differ among various racial/ethnic groups. This study demonstrated that endometriosis is less likely to be diagnosed in Black women and more likely to be diagnosed in Asian women, when compared to White women. Yet, the clinical presentation of the women included in these studies does seem to impact this trend. Namely, when comparing Black and White women and when endometriosis was diagnosed surgically or through self-report, we saw that Black women were less likely to have a diagnosis of endometriosis. However, looking at the infertility population, there was no difference in likelihood of endometriosis diagnosis between Black and White women. This trend was different for Asian women - there was no difference in likelihood of endometriosis diagnosis between Asian and White women when the diagnosis was made surgically, by self-report, or in women presenting with infertility.

\section{Strengths}

A number of strengths in our meta-analysis should also be mentioned. This was the first review and meta-analysis examining the impact of race/ethnicity on the prevalence of endometriosis. We performed a broad search, including abstracts from grey (unpublished) literature. We attempted to decrease the heterogeneity of the included study populations by performing subgroup analyses by clinical presentation and year of study.

\section{Limitations}

Our findings must be interpreted in the context of study design. We noted high/moderate heterogeneity in all the main racial/ethnic categories that were analyzed. We elected to present the pooled data, and furthermore examine potential 
explanations for the heterogeneity by completing sub-group analysis using clinically relevant variables. This bias was partially reduced when subgroup analysis was performed with study stratification by clinical presentation of patients. Potential explanations for residual heterogeneity may include: differences in study type and design, different populations assessed, variability in method of endometriosis diagnosis, as well as discrepancies in race/ethnicity designation between each study. Although, race and ethnicity categories can be established rather easily for research purposes, these designations are constantly evolving and therefore should be established in a thoughtful manner, perhaps ideally through self designation ${ }^{46}$. We should also note that race and ethnicity have different definitions. Race refers to a category of people who share certain inherited physical characteristics and suggests a biological basis for such traits within each group. Ethnicity generally refers to membership in a wide range of groups defined by culture, heritage, or national origin ${ }^{47}$. However, within medical literature these are often used concurrently, and we conformed to this in our review. Not all the studies included in our review specified how the race/ethnicity categories were defined, which is another possible source of heterogeneity identified. Although we may consider racial groups to represent a genetic construct as well, research does show abundant genetic diversity within racial groups ${ }^{48}$. This may be especially true when broad heterogenous populations are grouped together, such as the Asian group.

Other limitations of this review include suboptimal comparability between groups, as seen in the quality assessment analysis, and lack of adjustment for confounding variables. In particular, we are concerned about the confounding potential of socioeconomic status, which is closely related to race/ethnicity and may impact the diagnosis of endometriosis through a patient's ability to access healthcare ${ }^{10}$. 
We saw evidence of bias reported in the likelihood of endometriosis of Black women compared to White women, which may be attributable to publication or language bias. As there existed a strong belief that endometriosis is less prevalent in Black compared to White ${ }^{49}$, it is possible that small studies suggesting different conclusions were less likely to be selected for publication.

\section{Interpretation}

The above findings highlight the need to investigate the variation in disease presentation among women of various race/ethnicities. Since the main presenting symptomatology of endometriosis often includes pelvic pain ${ }^{37}$, a symptom which may be influenced by psychosocial factors ${ }^{38,39}$ women of different ethnic and cultural backgrounds with endometriosis likely have a different clinical presentation ${ }^{40}$. This is suggested in our results where the likelihood of endometriosis diagnosis among women of different ethnicities is partially influenced by the mode of diagnosis. Diagnosis of endometriosis may be particularly complex and sensitive to influence of external factors as it typically takes 7-10 years for a woman to be diagnosed with this condition ${ }^{41}$. Endometriosis is also a heterogenous condition and newer literature suggests that race/ethnicity may influence disease severity, namely with Asian women being more likely to be diagnosed with stage III/IV endometriosis, compared to White women ${ }^{40}$. Currently there is little effort in the literature to explore the diagnostic journey for women with endometriosis through a culturally sensitive lens.

When interpreting the potential implication of our findings for the clinician and patients, we must consider the historical journey of endometriosis as a clinical entity. The early literature about endometriosis emphasized a strong belief that endometriosis was a disease of White women who delayed childbearing ${ }^{33,42-45}$. Although these theories have since been scrutinized for methodological flaws and social bias, we cannot 
emphatically conclude that this bias no longer exists. Although our findings suggest that the likelihood of endometriosis diagnosis appears to be lower in Black women compared to White women, this may be due to a difference in presenting symptoms among various race/ethnicities or a residual implicit bias among health care providers to consider this diagnosis less likely in Black women. As such, we cannot confidently conclude that the prevalence of endometriosis is also lower in Black women.

\section{CONCLUSION}

Although there does appear to be variation in prevalence of endometriosis among various ethnic groups, the literature on this topic is insufficient to draw strong conclusions as many studies on this topic have significant methodological limitations. Importantly, there has been little focus on the potential impact of ethnicity on the clinical presentation of endometriosis, which should be the focus of further research. Health care providers must strive to provide culturally sensitive care to women that they treat, recognizing that women of different ethnicities may present with different symptomatology.

Disclosures of interests: OB, MIY, LS, and TF have no conflicts to declare. SS has participated in a speaker's bureau and received research grants and consulting fees from Bayer Pharma, Allergan, and AbbVie. S.S. Singh has also received consulting fees from Cooper Surgical. The authors confirm these sponsorships had no involvement in this study.

Completed disclosure of interest forms are available to view online as supporting information.

This article is protected by copyright. All rights reserved. 
Contribution to Authorship: OB was involved in study conceptualization, planning, data extraction and analysis, interpretation of findings and primary writer of the manuscript. MIY and TF contributed to data extraction and analysis. LS contributed to planning and data extraction. SS was involved in study conceptualization and interpretation of findings. All authors contributed to final manuscript.

Ethics Approval: Not applicable.

\section{Funding: None.}

\section{REFERENCES}

1. Waller KG, Lindsay P, Curtis P, Shaw RW. The prevalence of endometriosis in women with infertile partners. Eur J Obstet Gynecol Reprod Biol. 1993 Feb;48(2):135-9.

2. Rawson JM. Prevalence of endometriosis in asymptomatic women. J Reprod Med. 1991 Jul;36(7):513-5.

3. $\quad$ Eskenazi B, Warner ML. Epidemiology of endometriosis. Obstet Gynecol Clin North Am. 1997 Jun;24(2):235-58.

4. Nnoaham KE, Hummelshoj L, Webster P, d'Hooghe T, de Cicco Nardone F, de Cicco Nardone $\mathrm{C}$, et al. Impact of endometriosis on quality of life and work productivity: a multicenter study across ten countries. Fertil Steril. 2011 Aug;96(2):366-73 e8.

5. Meuleman C, Vandenabeele B, Fieuws S, Spiessens C, Timmerman D, D'Hooghe T. High prevalence of endometriosis in infertile women with normal ovulation and normospermic partners. Fertil Steril. 2009 Jul;92(1):68-74.

6. De Graaff AA, D'Hooghe TM, Dunselman GA, Dirksen CD, Hummelshoj L, Consortium WE, et al. The significant effect of endometriosis on physical, mental and social wellbeing: results from an international cross-sectional survey. Hum Reprod. 2013 Oct;28(10):2677-85.

7. Matsuzaki S, Canis M, Pouly JL, Rabischong B, Botchorishvili R, Mage G. Relationship between delay of surgical diagnosis and severity of disease in patients with symptomatic deep infiltrating endometriosis. Fertil Steril. 2006 Nov;86(5):1314-6; discussion 7.

8. Ballard K, Lowton K, Wright J. What's the delay? A qualitative study of women's experiences of reaching a diagnosis of endometriosis. Fertil Steril. 2006 Nov;86(5):1296-301.

9. Smith GD, Chaturvedi N, Harding S, Nazroo J, Williams R. Ethnic inequalities in health: A review of UK epidemiological evidence. Critical Public Health. 2000 2000/12/01;10(4):375-408.

10. Williams DR, Mohammed SA, Leavell J, Collins C. Race, socioeconomic status, and health: complexities, ongoing challenges, and research opportunities. Ann N Y Acad Sci. 2010 Feb;1186:69101.

11. Novak E, Jones GS, Novak ER. Endometriosis. In: Textbook of gynecology. 6th ed. Baltimore, MD: Williams and Wilkins; 1961: 247-250.

12. Kistner RW. Endometriosis. In: Gynecology; principles and practice. 2d ed. Chicago, IL:

Mosby; 1971: 432-456. p. 432-56.

This article is protected by copyright. All rights reserved. 
13. Hasson HM. Incidence of endometriosis in diagnostic laparoscopy. J Reprod Med. 1976 Mar;16(3):135-8.

14. Brzezinski A, Koren Z, Kedar S. Contribution to the problem of the etiology of endometriosis.

Isr Med J. 1962 May-Jun;21:111-7.

15. Cavanagh WV. Fertility in the etiology of endometriosis. Am J Obstet Gynecol. 1951

Mar;61(3):539-47.

16. Missmer SA, Hankinson SE, Spiegelman D, Barbieri RL, Marshall LM, Hunter DJ. Incidence of laparoscopically confirmed endometriosis by demographic, anthropometric, and lifestyle factors.

Am J Epidemiol. 2004 Oct 15;160(8):784-96.

17. Arumugam K, Templeton AA. Endometriosis and race. Aust N Z J Obstet Gynaecol. 1992 May;32(2):164-5.

18. Miyazawa K. Incidence of endometriosis among Japanese women. Obstet Gynecol. 1976 Oct;48(4):407-9.

19. Vigano P, Somigliana E, Panina P, Rabellotti E, Vercellini P, Candiani M. Principles of phenomics in endometriosis. Hum Reprod Update. 2012 May-Jun;18(3):248-59.

20. Liberati A, Altman DG, Tetzlaff J, Mulrow C, Gotzsche PC, Ioannidis JP, et al. The PRISMA statement for reporting systematic reviews and meta-analyses of studies that evaluate health care interventions: explanation and elaboration. J Clin Epidemiol. 2009 Oct;62(10):e1-34.

21. Wells GAS BOC, D.; Peterson, J.; Welch, V.; Losos, M.;Tugwell, P. . The Newcastle-Ottawa Scale (NOS) for assessing the quality of nonrandomised studies in meta-analyses.

22. Stang A. Critical evaluation of the Newcastle-Ottawa scale for the assessment of the quality of nonrandomized studies in meta-analyses. Eur J Epidemiol. 2010 Sep;25(9):603-5.

23. Campbell S, Raza M, Pollack AZ. Perfluoroalkyl substances and endometriosis in US women in NHANES 2003-2006. Reprod Toxicol. 2016 Oct;65:230-5.

24. Green JA, Robins JC, Scheiber M, Awadalla S, Thomas MA. Racial and economic demographics of couples seeking infertility treatment. Am J Obstet Gynecol. 2001 May;184(6):10802.

25. Hsu AL, Sinaii N, Segars J, Nieman LK, Stratton P. Relating pelvic pain location to surgical findings of endometriosis. Obstet Gynecol. 2011 Aug;118(2 Pt 1):223-30.

26. Kvaskoff M, Han J, Qureshi AA, Missmer SA. Pigmentary traits, family history of melanoma and the risk of endometriosis: a cohort study of US women. Int J Epidemiol. 2014 Feb;43(1):255-63.

27. Karmon A, Hailpern SM, Neal-Perry G, Green RR, Santoro N, Polotsky AJ. Association of ethnicity with involuntary childlessness and perceived reasons for infertility: baseline data from the Study of Women's Health Across the Nation (SWAN). Fertil Steril. 2011 Nov;96(5):1200-5 e1.

28. Lloyd FP. Endometriosis in the Negro Woman: A Five Year Study. Am J Obstet Gynecol. 1964 Jun 15;89:468-9.

29. Maclaran K, Agarwal N, Odejinmi F. Co-existence of uterine myomas and endometriosis in women undergoing laparoscopic myomectomy: risk factors and surgical implications. J Minim Invasive Gynecol. 2014 Nov-Dec;21(6):1086-90.

30. Mowers EL, Lim CS, Skinner B, Mahnert N, Kamdar N, Morgan DM, et al. Prevalence of Endometriosis During Abdominal or Laparoscopic Hysterectomy for Chronic Pelvic Pain. Obstet Gynecol. 2016 Jun;127(6):1045-53.

31. Patel AP, Patel JA, Cruz M, Gupte-Shah A, Garcia Velasco JA, Banker MR. Ethnicity is an independent predictor of IVF-ICSI outcome: a study of 5,549 cycles in Spain and India. Gynecol Endocrinol. 2016 Oct;32(10):819-22.

32. Sangi-Haghpeykar H, Poindexter AN, 3rd. Epidemiology of endometriosis among parous women. Obstet Gynecol. 1995 Jun;85(6):983-92.

33. Scott RB, Te LR. External endometriosis--the scourge of the private patient. Ann Surg. 1950 May;131(5):697-720.

34. Yamamoto A, Johnstone EB, Bloom MS, Huddleston HG, Fujimoto VY. A higher prevalence of endometriosis among Asian women does not contribute to poorer IVF outcomes. J Assist Reprod Genet. 2017 Jun;34(6):765-74.

35. Zhao SZ, Wong JM, Davis MB, Gersh GE, Johnson KE. The cost of inpatient endometriosis treatment: an analysis based on the Healthcare Cost and Utilization Project Nationwide Inpatient Sample. Am J Manag Care. 1998 Aug;4(8):1127-34.

36. Bougie O, Singh SS, Chen I, McCarthy EP. Relationship between race/ethnicity and hysterectomy outcomes for benign gynecologic conditions. J Minim Invasive Gynecol. 2018 May 25. 37. Leyland N, Casper R, Laberge P, Singh SS.. Endometriosis: diagnosis and management. J Obstet Gynaecol Can. 2010 Jul;32(7 Suppl 2):S1-32.

This article is protected by copyright. All rights reserved. 
38. Marciani RD, Humphries LL, Maxwell EN, Jr., Costich JF, Wiegert T, Engelberg J. Chronic pain: economic, psychosocial, ethical, preventive, and medical aspects. South Med J. 1985 Jun;78(6):719-24.

39. Fry RP, Crisp AH, Beard RW, McGuigan S. Psychosocial aspects of chronic pelvic pain, with special reference to sexual abuse. A study of 164 women. Postgrad Med J. 1993 Jul;69(813):566-74.

40. Williams C, Long AJ, Noga H, Allaire C, Bedaiwy MA, Lisonkova S, et al. East/South East Asian Ethnicity and Moderate-to-Severe Endometriosis. J Minim Invasive Gynecol. 2018 Jun 20. 41. Hudelist G, Fritzer N, Thomas A, Niehues C, Oppelt P, Haas D, et al. Diagnostic delay for endometriosis in Austria and Germany: causes and possible consequences. Hum Reprod. 2012 Dec;27(12):3412-6.

42. Meigs JV. Endometriosis, a possible aetiological factor. Surgery, Gynaecology and Obstetrics 1938;67:253-5.

43. Meigs JV. An interest in endometriosis and its consequences: President's address. American Journal of Obstetrics \& Gynecology. 1960;79(4):625-35.

44. Blinick G, Merendino VJ. The infrequency of pelvic endometriosis in Negro women. Am J Surg. 1951 Jun;81(6):635-6.

45. $\quad$ Meigs JV. Endometriosis-Its Significance. Ann Surg. 1941 Nov;114(5):866-74.

46. Winker MA. Measuring race and ethnicity: why and how? JAMA. 2004 Oct 6;292(13):1612-4.

47. Kaplan JB, Bennett T. Use of race and ethnicity in biomedical publication. JAMA. 2003 May 28;289(20):2709-16.

48. Sankar P, Cho MK. Genetics. Toward a new vocabulary of human genetic variation. Science. 2002 Nov 15;298(5597):1337-8.

49. Bougie O, Healey J, Singh SS. Behind the Times: Revisiting Endometriosis and Race. Am J Obstet Gynecol. 2019 Feb 6.

\section{TABLES/FIGURE CAPTION LIST}

Table 1: Description of studies included in the systematic review +/- meta-analysis.

Study type: RC (retrospective cohort), PC (prospective cohort), CS (cross sectional

survey) and CC (case control). Endo - endometriosis; CD - clinical diagnosis; SD -

surgical diagnosis; SR - self-report; HD - histologic diagnosis; Dx - diagnosis; Comp -

comparability.

Figure 1: Difference in prevalence of endometriosis in (A) White vs. Black women, (B)

White vs. Asian women and (C) White vs. Hispanic women, with White being the

reference category.

This article is protected by copyright. All rights reserved. 
Figure 2: Difference in prevalence of endometriosis in White vs. Black women, with White being the reference category, subgroup analysis by (A) clinical presentation and (B) study date.

Figure 3: Difference in prevalence of endometriosis in White vs. Asian women, with White being the reference category, subgroup analysis by (A) clinical presentation and (B) study date.

This article is protected by copyright. All rights reserved. 


\begin{tabular}{|c|c|c|c|c|c|c|c|c|c|c|c|c|}
\hline & Year & Design & & 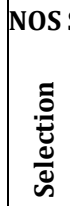 & छे & 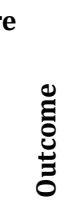 & 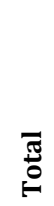 & Sample Size & Population & $\begin{array}{l}\text { Diagnosis of } \\
\text { Endometriosis }\end{array}$ & $\begin{array}{l}\text { Identification } \\
\text { of Race }\end{array}$ & Method of Analysis \\
\hline Arumugam ${ }^{17}$ & 1992 & $\mathrm{RC}$ & SD & 1 & 0 & 2 & 3 & 666 & Infertility patients from UK and South East Asia & Surgical & Unspecified & Descriptive statistics \\
\hline Bougie $^{36}$ & 2018 & CS & CD & 3 & 2 & 2 & 7 & 114,719 & Hysterectomy Patients in National Inpatient Sample Database & ICD coding & Self-identified & Weighted survey sampling \\
\hline Brzezinski ${ }^{14}$ & 1962 & $\mathrm{RC}$ & HD & 1 & 0 & 1 & 2 & 19,670 & $\begin{array}{l}\text { Women hospitalized in Department of OB/GYN in Hadassah } \\
\text { University Hospital }\end{array}$ & Surgical & Unspecified & Descriptive statistics \\
\hline Campbell ${ }^{23}$ & 2016 & CS & SR & 2 & 0 & 2 & 4 & 20,470 & $\begin{array}{l}\text { Women responding to National Health and Nutrition Examination } \\
\text { Survey (NHANES) cycles }\end{array}$ & Self-reported & Self-reported & $\begin{array}{l}\text { Weighted survey sampling } \\
\text { logistic regression }\end{array}$ \\
\hline Cavanagh 15 & 1951 & $\mathrm{RC}$ & HD & 0 & 0 & 2 & 2 & 5,159 & Women having surgery in Sloan Hospital, US & Surgical/histological & Unspecified & Descriptive statistics \\
\hline Green $^{24}$ & 2011 & $\mathrm{RC}$ & CD & 1 & 0 & 1 & 2 & 754 & New infertility patients in 2 infertility clinics in Cincinnati, Ohio & Unspecified & Unspecified & Logistic regression \\
\hline Hasson $^{13}$ & 1976 & $\mathrm{RC}$ & SD & 2 & 0 & 1 & 3 & 522 & Women having surgery with primary author & Surgical & Unspecified & Descriptive statistics \\
\hline $\mathrm{Hsu}^{25}$ & 2011 & PC & HD & 2 & 0 & 3 & 5 & 133 & $\begin{array}{l}\text { Women having surgery at National Institutes of Health (NIH) } \\
\text { Clinical Center or Georgetown }\end{array}$ & Surgical & Unspecified & Logistic regression \\
\hline Kvaskoff 26 & 2014 & PC & SR & 3 & 2 & 1 & 6 & $\begin{array}{l}1,212,499 \\
\text { person-years }\end{array}$ & Nurses' Health Study II participants & Surgical & Self-reported & Time-to-event \\
\hline Karmon $^{27}$ & 2011 & CS & SR & 3 & 0 & 2 & 5 & 3,149 & $\begin{array}{l}\text { SWAN study, a multiethnic, multicenter longitudinal study of } \\
\text { women as they progress through menopausal transition }\end{array}$ & Self-reported & Self-report & Logistic regression \\
\hline Lloyd $^{28}$ & 1964 & $\mathrm{RC}$ & SD & 1 & 0 & 0 & 1 & 803 & All gynecology private patients at St. Vincent's Hospital, Indiana & Surgical/histological & Unspecified & Descriptive statistics \\
\hline Maclaran 29 & 2014 & $\mathrm{RC}$ & SD & 3 & 0 & 2 & 5 & 212 & Women undergoing myomectomy at London University Hospital & Surgical & Unspecified & Descriptive statistics \\
\hline Missmer ${ }^{16}$ & 2004 & PC & SD & 3 & 2 & 2 & 7 & $\begin{array}{l}726,205 \\
\text { person-years }\end{array}$ & Nurses' Health Study I participants & Surgical & Self-reported & Time to event \\
\hline Miyazawa ${ }^{18}$ & 1976 & $\mathrm{RC}$ & SD & 1 & 1 & 1 & 3 & 2,177 & Women admitted to hospitals in Hawaii (2) and Japan (1) & Surgical & Unspecified & Descriptive statistics \\
\hline Nnoaham $^{4}$ & 2011 & CS & SD & 3 & 0 & 2 & 5 & 1,418 & $\begin{array}{l}\text { Global Study of Women's Health Multicenter cohort undergoing } \\
\text { surgery }\end{array}$ & Surgical & Self-reported & Logistic regression \\
\hline
\end{tabular}

This article is protected by copyright. All rights reserved. 


\begin{tabular}{|c|c|c|c|c|c|c|c|c|c|c|c|c|}
\hline Patel $^{31}$ & 2016 & $\mathrm{RC}$ & SR & 0 & 0 & 1 & 1 & 4,549 & Women undergoing IVF/ICSI treatment cycles in Spain and India & Not specified & Unspecified & Descriptive statistics \\
\hline $\begin{array}{l}\text { Sangi- } \\
\text { Haghpeykar }^{32}\end{array}$ & 1995 & $\mathrm{CC}$ & SD & 1 & 2 & 2 & 5 & 630 & $\begin{array}{l}\text { Women undergoing laparoscopic tubal sterilization at Baylor } \\
\text { College of Medicine in Houston }\end{array}$ & Surgical & Self-reported & Descriptive statistics \\
\hline $\operatorname{Scott}^{33}$ & 1950 & $\mathrm{RC}$ & SD & 1 & 0 & 1 & 2 & 516 & Women undergoing surgery at John Hopkins Hospital & Surgical & Unspecified & Descriptive statistics \\
\hline Yamamoto $^{34}$ & 2017 & $\mathrm{RC}$ & $\mathrm{CD}$ & 1 & 1 & 2 & 4 & 1,011 & Patients undergoing IVF at University of California, San Francisco & Clinical +/- surgical & Unspecified & Descriptive statistics \\
\hline Zhao 35 & 1998 & PC & CD & 3 & 0 & 1 & 4 & $3,289,831$ & National Inpatient Sample Database & ICD coding & Self-reported & Weighted survey sampling \\
\hline
\end{tabular}

This article is protected by copyright. All rights reserved. 
(A) Black White

Odds Ratio

Odds Ratio

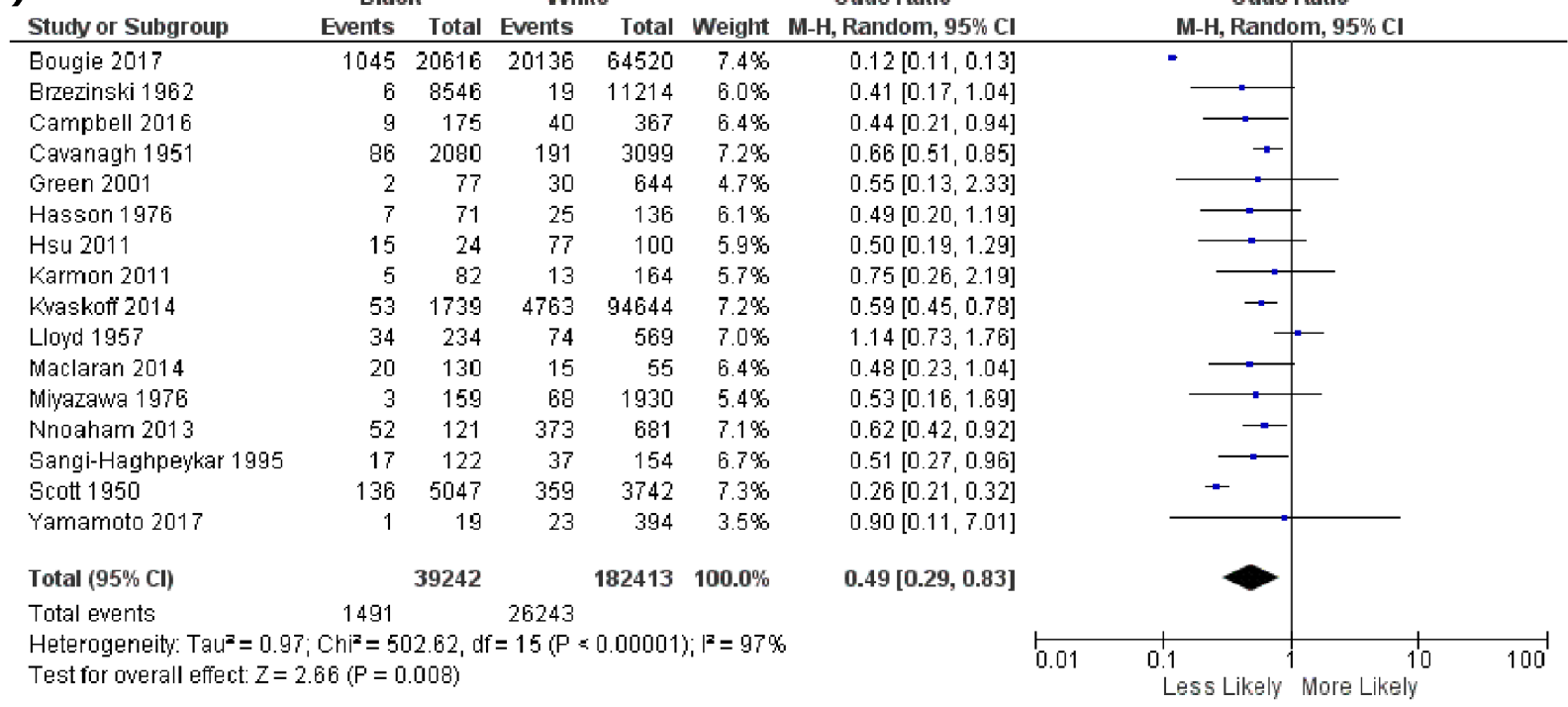

(B) Asian White Odds Ratio Events Total Events Total Weight $\mathrm{M}-\mathrm{H}, \mathrm{Random}, 95 \% \mathrm{CI}$

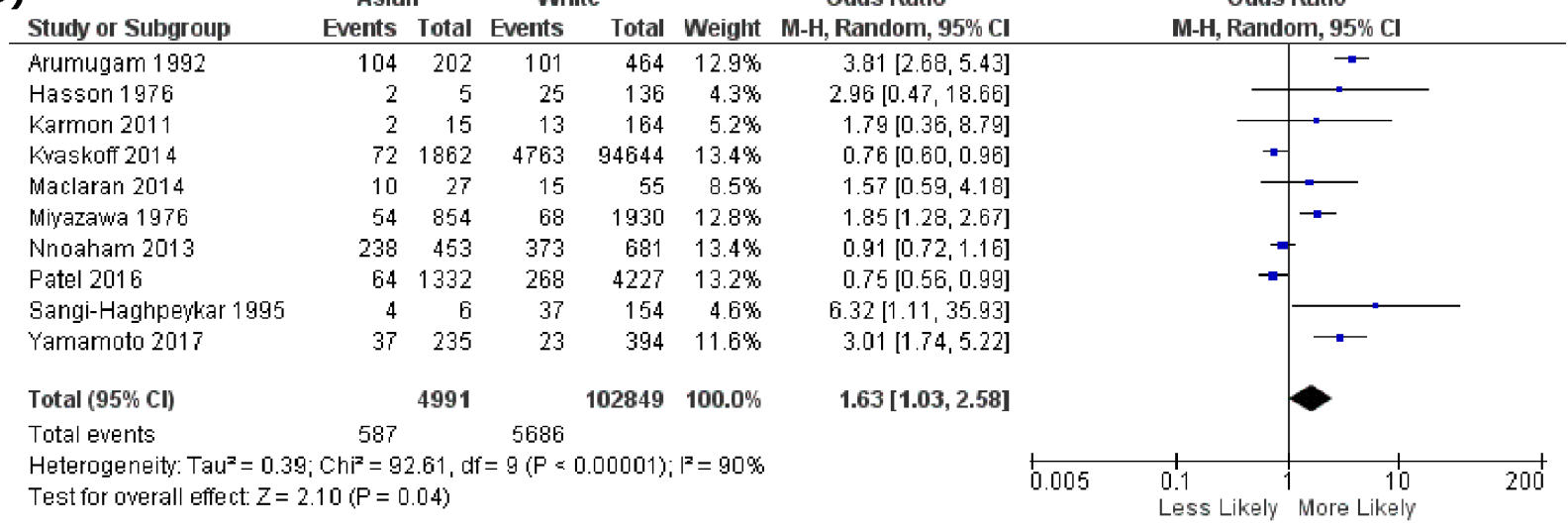

(C) Hispanic White Odds Ratio Odds Ratio

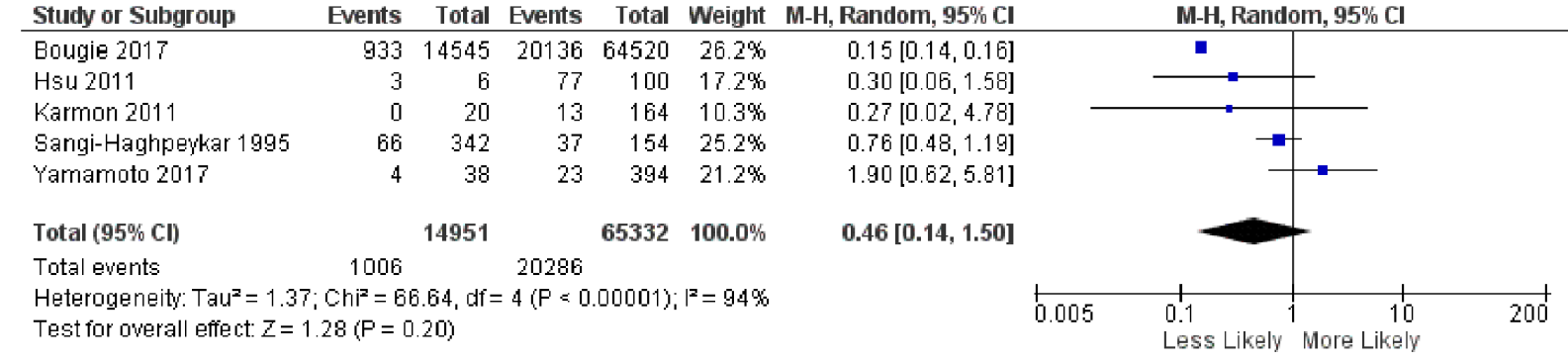

This article is protected by copyright. All rights reserved. 
(A)

Biack White

Odds Ratio

Study or Subgroup

Events Iotal Events Total Weight M-H, Random, 95\% Cl

M-H, Random, 95\% Cl

Green 2001

$\begin{array}{lllll}2 & 77 & 30 & 644 & 4.7 \%\end{array}$

$0.55[0.13,2.33$

Yamamoto 2017

$\begin{array}{llll}19 & 23 & 394 & 3.5^{\circ}\end{array}$

$0.90[0.11,7.01$

Subtotal ( $95 \%$ Cl)

$1038 \quad 8.2 \%$

$0.64[0.20,2.11]$

Heterogeneity: Tau $^{2}=0.00 ; \mathrm{ChF}^{\mathbf{2}}=0.15, \mathrm{df}=1(\mathrm{P}=0.70)_{i}{ }^{\mathbf{z}}=0 \%$

Test for overall effect: $Z=0.73(\mathrm{~F}=0.47)$

1.2.3 Pres: Self Report

Campbell 2016

Karmon 2011

Kaskoff 2014

Subtotal $(95 \% \mathrm{Cl})$

Total events

$9 \quad 175 \quad 40 \quad 367 \quad 6.4 \%$

$0.75[0.26,2.19$

$0.59[0.45,0.78$

$0.58[0.45,0.75]$

Heterogeneity: Tau $^{2}=0.00 ; \mathrm{Ch}^{2}=0.76, \mathrm{df}=2(\mathrm{P}=0.69) ;{ }^{2}=0 \%$

Test for overall effect: $Z=4.23(P=0.0001)$

1.2.4 Pres: Surgical

Bougie 2017

Erzezinski 1962

Cavanagh 1951

$1045 \quad 20616 \quad 20136 \quad 64520 \quad 7.4 \%$

$0.12[0.11,0.13]$

$0.41[0.17,1.04]$

$0.66[0.51,0.85]$

$0.49[0.20,1.19]$

$0.50[0.19,1.29$

$1.14[0.73,1.76]$

$0.48[0.23,1.04]$

$0.53[0.16,1.69]$

$0.62[0.42,0.92]$

$0.51[0.27,0.96$

$0.26[0.21,0.32$

$0.45[0.25,0.83]$

Gangi-Haghpeykar 199

Scott 1950

$\begin{array}{rrrrr}17 & 122 & 37 & 154 & 6.7 \%\end{array}$

$\begin{array}{lllll}136 & 5047 & 359 & 3742 & 7.3 \%\end{array}$

$86200 \quad 725 \%$

Total events

1421 21374

Heterogeneity. Tau $^{2}=0.95 ; \mathrm{ChF}^{2}=391.45, \mathrm{df}=10(\mathrm{P}=0.00001)_{;} \mathrm{I}^{2}=97 \%$ Test for overall effect: $Z=2.54$ ( $P=0.01$ )

Total ( $95 \% \mathrm{Cl}$ )

39242

Total events

1491

$182413100.0 \%$

Heterogeneity: $\mathrm{Tau}^{2}=0.97 ; \mathrm{Ch}^{2}=502.62, \mathrm{df}=15(\mathrm{P}<0.00001) ; \mathrm{I}^{2}=97 \%$

Test for overall effect: $Z=2.66(P=0.008)$

Test for subgroun differences: $\mathrm{Chi}^{2}=0.60, \mathrm{df}=2(\mathrm{~F}=0.74) . \mathrm{I}^{2}=0 \%$

$0.49[0.29,0.83]$

\begin{tabular}{c|c}
$\longrightarrow$ \\
\hline \\
\hline
\end{tabular}

(B)

Study or Subgroup

Black White

Odds Ratio

1.4.2 Before 1990

Events Total Events Total Weight $\mathrm{M}-\mathrm{H}$, Random, 95\% Cl

Brzexinski 196

$\begin{array}{lllll}6 & 8546 & 19 & 11214 & 6.0 \%\end{array}$

Cavanagh 1951

$\begin{array}{lllll}86 & 2080 & 191 & 3099 & 7.2 \%\end{array}$

Hasson 1976

$\begin{array}{lllll}7 & 71 & 25 & 136 & 6.1 \%\end{array}$

Lloyd 1957

Miyarawa 1976

Scott 1950

Subtotal $(95 \% \mathrm{Cl})$

$34 \quad 234$

$\begin{array}{lll}25 & 136 & 6.1 \% \\ 74 & 569 & 7.0 \%\end{array}$

$136 \quad 5047$

$1930 \quad 5.4 \%$

$\begin{array}{rrr}68 & 1930 & 5.4 \% \\ 359 & 3742 & 7.3 \%\end{array}$

$2069039.1 \%$

Heterogeneity: Tau $^{2}=0.42 ; \mathrm{ChF}^{\mathrm{F}}=52.60, \mathrm{df}=5(\mathrm{P}=0.00001) ; \mathrm{I}^{2}=91 \%$

Test for overall effect: $Z=2.15(\mathrm{P}=0.03)$

1.4.3 After 1990

Bougie 2017

Campbell 2016

Green 2001

Hsu 2011

Karmon 2011

Kuakofi 2014

Waclaran 2014

Nnoaham 2013

Sangi-Haghpewkar 1995

Yamamoto 2017

Subtotal $(95 \% \mathrm{Cl})$

Total events

$\begin{array}{lllll}1045 & 20616 & 20136 & 64520 & 7.4 \%\end{array}$

$0.12[0.11,0.13$

$0.44[0.21,0.94]$

$0.55[0.13,2.33]$

$0.50[0.19,1.29]$

$0.75[0.26,2.19$

$0.59[0.45,0.78]$

$0.48[0.23,1.04]$

$0.62[0.42,0.92$

$0.51[0.27,0.96$

$0.90[0.11,7.01]$

$0.47[0.23,0.98]$

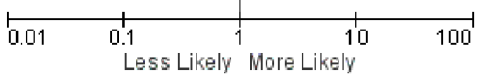

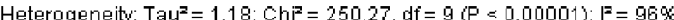
Test for overall effect: $Z=2.01\left(\mathrm{P}^{\prime}=0.04\right)$

Total $(95 \% \mathrm{Cl})$

Total events

$182413 \quad 100.0 \%$

Heterogeneity $\mathrm{Tau}^{2}=0.97 \cdot \mathrm{ch}^{\mathbf{2}}=50262 \mathrm{df}=15(\mathrm{P}=0.00001) \mathrm{l}^{2}=97 \%$

Test for overall effect: $Z=2.66(\mathrm{P}=0.008)$

Test for subaroup differences: $\mathrm{Chi}^{2}=0.05, \mathrm{df}=1(\mathrm{~F}=0.82), \mathrm{I}^{\mathrm{z}}=0 \%$

$0.49[0.29,0.83]$

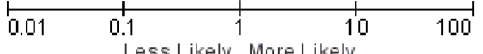

This article is protected by copyright. All rights reserved. 
(A)

Asian White

Odds Ratio

Study or Subgroup

Events Total Events Total Weight M-H, Random, 95\% Cl

M-H, Random, 95\% Cl

7.2.2 Pres: Infertility

$\begin{array}{lllll}104 & 202 & 101 & 464 & 12.9 \%\end{array}$

$3.81[2.68,5.43]$

Pate 2016

$64 \quad 1392 \quad 260 \quad 4227 \quad 13.2 \%$

$0.75[0.56,0.99]$

Yamamoto 2017

$37 \quad 23$

$301[1.74,5.22]$

Subtotal $(95 \%$ Cl)

$\begin{array}{lcc}\text { Total events } & 205 & 392 \\ \text { Heterogeneity: } \text { Tau }^{2}=1.01 ; \mathrm{ChF}^{2}=57.04, \mathrm{df}=2(\mathrm{P}=0.00001) ; \mathrm{P}^{2}=96 \%\end{array}$

$5085 \quad 37.7 \%$

$2.03[0.64,6.47]$

Test for overall effect: $z=1.19(\mathrm{P}=0.23)$

7.2.3 Pres: Self Report

$\begin{array}{lrrrrrr}\text { Karmon 2011 } & 2 & 15 & 13 & 164 & 5.2 \% & 1.79[0.36,8.79] \\ \text { Kraskoff 2014 } & 72 & 1862 & 4763 & 94644 & 13.4 \% & 0.76[0.60,0.96] \\ \text { Subtotal (95\% cl) } & & 1877 & & \mathbf{9 4 8 0 8} & \mathbf{1 8 . 6 \%} & \mathbf{0 . 8 0}[0.54,1.19] \\ \text { Total events } & 74 & & 4776 & & & \end{array}$

Heterogeneity: $\operatorname{Tau}^{2}=0.03 ; \mathrm{Ch}^{2}=1.09, \mathrm{df}=1(\mathrm{P}=0.30) ; \mathrm{i}^{2}=8 \%$

Test for owerall effect: $Z=1.10(\mathrm{P}=0.27)$

\subsubsection{Pres: Surgical}

Hasson 1976

Waclaran 2014

Miyazawa 1976

Nnoaham 2013

Sangi-Haghpeykar 1995

Subtotal $(95 \%$ Cl)

$\begin{array}{rrrrr}2 & 5 & 25 & 136 & 4.3 \% \\ 10 & 27 & 15 & 55 & 8.5 \% \\ 54 & 854 & 68 & 1930 & 12.8 \% \\ 238 & 453 & 373 & 681 & 13.4 \% \\ 4 & 6 & 37 & 154 & 4.6 \% \\ & 1345 & & 2956 & 43.6 \%\end{array}$

$2.96[0.47,18.66]$

$1.57[0.59,4.18]$

$1.85[1.28,2.67]$

$0.91[0.72,1.16]$

$6.32[1.11,35.93]$

$1.61[0.92,2.82]$

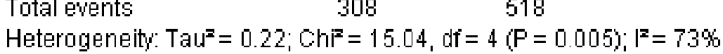

Test for overall effect: $Z=1.66(\mathrm{P}=0.1 \mathrm{D})$

Total $(95 \% \mathrm{Cl})$

$587^{4991} 5696$

Heterogeneity: Ta $u^{2}=0.39 ; \mathrm{ChP}^{2}=92.61, \mathrm{df}=9(\mathrm{P}=0.00001)_{1} \mathrm{P}^{2}=90 \%$

Test for owerall effect: $Z=2.10(P=0.04)$

Test for subaroup differences: ch ${ }^{2}=5.25, \mathrm{df}=2(\mathrm{P}=0.07), \mathrm{l}^{2}=61.9 \%$

1.63 [1.03, 2.58]

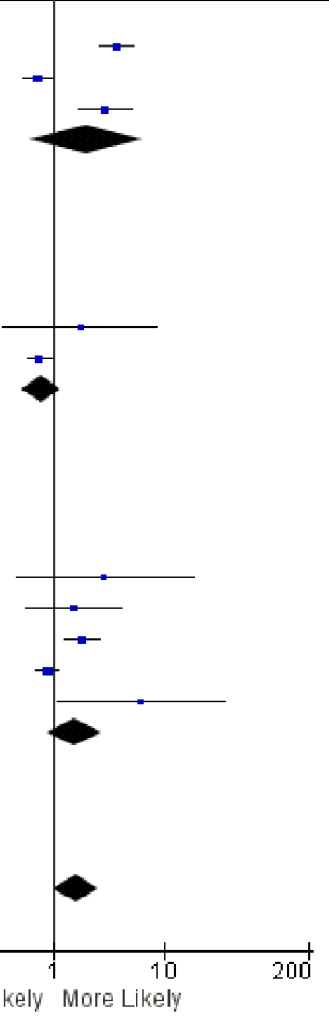

(B)

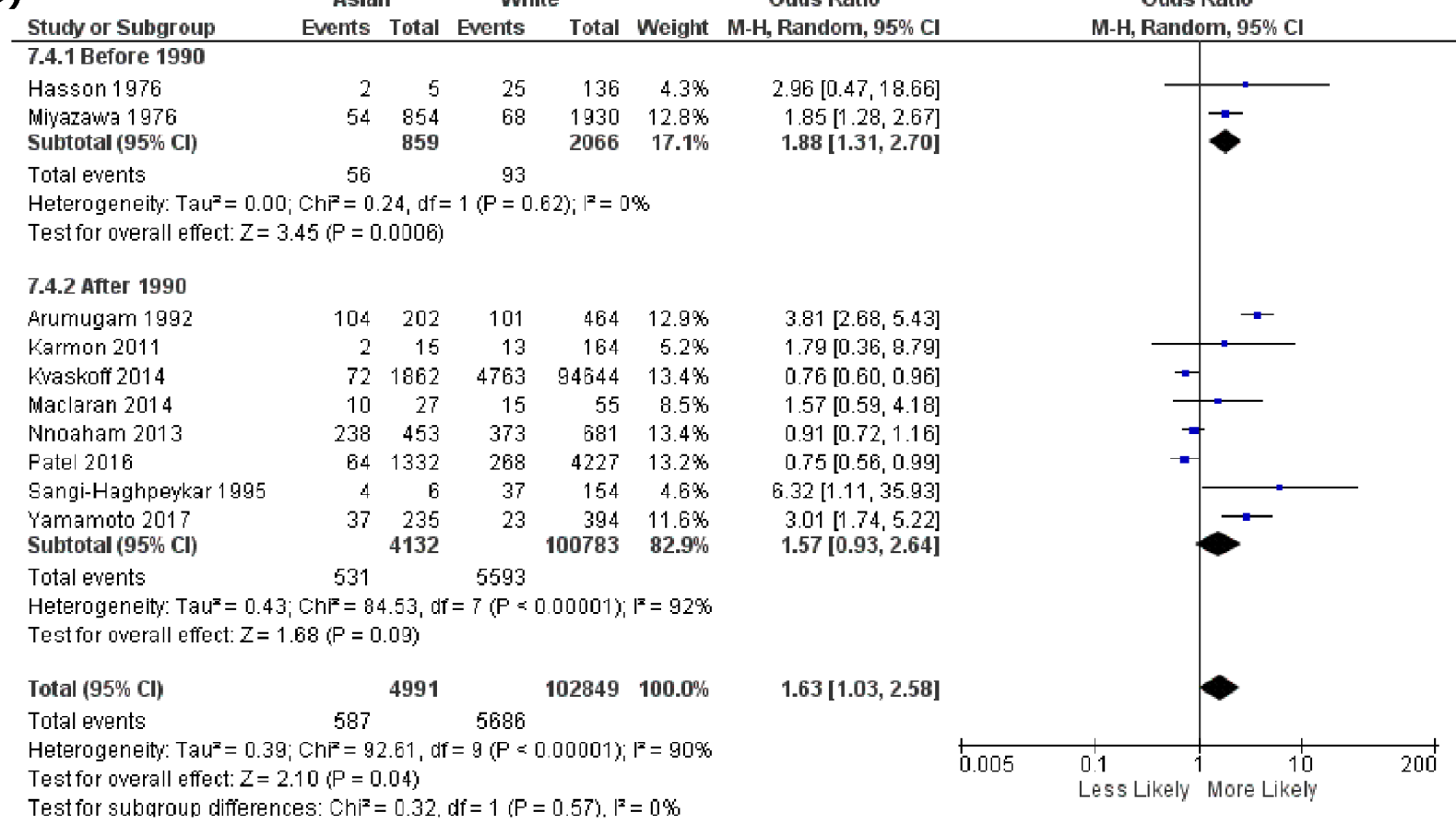

This article is protected by copyright. All rights reserved. 